\title{
Silence Behavior in Public and Private Higher Learning Institutions in Selangor, Malaysia
}

\author{
Asma Rina Abdul Rahman \\ Faculty of Business \& Accountancy, University Selangor (UNISEL), Malaysia \\ Corresponding Author: asmarina@unisel.edu.my \\ Suria Abu Basar \\ Faculty of Business \& Accountancy, University Selangor (UNISEL), Malaysia \\ suria@unisel.edu.my
}

\section{Aznita Ahmad}

Faculty of Business \& Accountancy, University Selangor (UNISEL), Malaysia aznita@unisel.edu.my

\section{Noor Ayuernie Ibrahim}

Faculty of Business \& Accountancy, University Selangor (UNISEL), Malaysia

noor_ayuernie@yahoo.com

\begin{abstract}
Silence behavior is a behavioural choice that can deteriorate or improve organisational performance. Silence can convey sharing information or disfavour and opposition, thus becoming a pressure mechanism for both individuals and organisations. This study was conducted to examine the extent of silence behavior and investigate the factors influencing silence behavior among staff in public as well as private universities in Selangor, Malaysia. Based upon a model of employee silence developed by Milliken et al. (2003), a survey was conducted with 136 academic and non-academic staff of public and private higher learning institutions in Selangor. Overall, the respondents reveal that they preferred to remain silence because they are not going to talk about sensitive issue and they need to preserve the dignity of higher management personnel before expressing any sensitive matter. Among the antecedents of silence behavior, the expected of negative impact and management practices have substantial influence. The findings of this study are consistent with the Face Negotiate Theory as the higher management personnel in fear receiving negative feedback from the middle level officers. Besides, fear of retaliation or being marginalized as well as being misunderstood as challenging the status of the higher management makes no one preferred to be as a whistle-blower to report the wrongdoing cases to the higher management. Some of them just ignored the incidence of wrongdoing happened to avoid the negative impact towards them.
\end{abstract}

Keywords: Silent Behavior, Expected of Negative Impact, Management Practice, Face Negotiation Theory. 


\section{INTRODUCTION}

Organizational silence is a new concept in the literature and was first introduced in the 2000 by Morrison and Milliken. While Morrison and Milliken (2000) defined the organizational silence as a collective phenomenon that impedes the development of a hazard and a pluralistic organization that hinder organizational change and development, Tangirala and Ramanujam (2008) defined it as not to share with others, and to keep themselves for the employees of businesses or organizations important situations, issues or events. In the context of Social Exchange Theory (Blau, 1964), organizational silence is an important organizational behavior issues that arise in lack of having the relationship equitable social change.

Employees' reluctance to speak up about work-related matters has been linked to many important individual and organizational outcomes such as decreased innovation, failure to address ethical transgressions, stress and depression, lower commitment and job satisfaction (Brinfield, 2013). In addition, withholding information is perceived to be an obstacle to organisational development and change (Dedahanov, Lee and Rhee, 2016), and can influence error correction and innovation (Jahanzeb, Fatima and Malik, 2018). Most of the members in the organisation are aware of the problems that occur in the organisation, but some of them choose not to take any action. Morrison and Milliken (2000) believed that silence is turned into a strong force in organizations but serious studies are not performed in this regard. Morrison and Milliken (2000) have shown that organizational silence is social phenomenon created in an organizational level and is affected by most of organizational features as decision making processes, management, culture and perceptions of employees. Commonly, there are three factors that cause silence behaviour (Milliken, Morrison and Hewlin, 2003). First, fear of being labelled as a negative attitude or cause organisational problems. Second, fear their relationship with chairman will be affected. Third, feel useless to voice their opinions as the action will not change the situation.

In the context of Higher Learning Institution in Malaysia, lots of the wrongdoing cases occurred but some of them are not reported to the top management. For instance, there was a case involving the misappropriation of research's budget allocation from the Ministry of Education by faculty members (Huzaila-Majid and Singaravelloo, 2017). This wrongdoing could be continued to indefinite period if there is no one's act as a whistleblower to report the truth to the top management. This scenario indicates that decision to remain silent is common among staff in the higher learning institutions. The main shortcoming in previous studies is the lack of information about employees' motives to be silent. These issues motivate this research to further discover the decision to remain silent in the Malaysian higher learning institutions environment. A key question that this study poses is why some staff often see things but keep that information to themselves? Fundamentally, what are the factors that associated with silence behavior among staff? This research explores the following objectives:

a) To identify the extent of silence behavior among staff.

b) To examine if there is any significant different in silence behavior among staff in different higher learning institutions.

c) To investigate the factors influencing silence behavior among staff at the higher learning institution.

\section{LITERATURE REVIEW}

There are a variety of reasons behind the fact that individuals cannot speak out their concerns and worries about several issues and problems. Next sub-sections discusses the factors 
influencing silence behavior suggested by Milliken et al. (2003) that are taken into consideration in this study.

\subsection{The Extent of Silence Behavior}

Individual's behavior is influenced by what happened in the surrounding (Kiffin-Petersen, 2018). Universities are expected not only to perform education and teaching, but also to be guiding institutions for cultural, economic and social development in order to raise the society's development level. For the accomplishment of these functions of universities, academicians should be able to express their opinions freely, concerning both functioning of universities and scholarly issues. However, findings of current studies demonstrate that academicians are hesitant to share their ideas, opinions and suggestions (Tülübaş and Celep, 2014; Yaman and Ruçlar, 2014). The dominance of bureaucratic mentality at universities might cause critical thinkers to bite back and prevent from expressing their opinions; in other words they retreat into organizational silence. Therefore, this study suggests that:

$H_{1}$ : The extent of silence behavior among the staff in the higher learning institution is high.

\subsection{Difference in Silence Behavior}

Demographic dissimilarity between top managers and subordinates among a factor that Bagheri, Zarei and Aeen (2012) hypothesized would increase the likelihood of management holding beliefs that contribute to silence. This variable is also likely to contribute more directly to a climate of silence by affecting the perceptions and beliefs of lower-level employees. Marcus (2000) performed a case study at a community college to examine how a diverse staff experienced the work place. Although findings from this study cannot be generalized, they underscore the importance of understanding how staff of color and women staff may perceive their institution's climate for diversity differently than whites and male staff. These findings are supported by Hurtado, Milem, Clayton-Pedersen and Allen (1998) assertion that racially and ethnically diverse administrators, students, and faculty tend to view the campus climate differently. For this reason, this study include a series of staff demographic profile to shed light on whether there is a difference in silence behavior across staff characteristics. Hence, this study predicts:

$\mathrm{H}_{2}$ : There is a significant difference in the silence behavior among staff in different higher learning institutions.

\subsection{Determinants of Silence Behavior}

Communication is the process of distributing information (Griffin, 2003). Failure to communicate over will lead problems among the leaders to make right decision making due to lack of essential information from the bottom level (Juhari, 1996). In a bureaucracy organisation, communication must be in line with the government channels (Deverell, Olsson, Wagnsson, Hellman and Johnsson, 2015). The formal communication channels are part of the organisation's structure channelling messages according to rules, customs, and distribution of authority, ranks, and type of tasks in the organisation (Juhari, 1996). In the higher learning institution context, the importance of information for the decision-making process cannot be denied as it involves the national education. Any mistake had been made based on false or incomplete information will affect the students and organisation as well. This study conjectures that:

$\mathrm{H}_{3}$ : Communication skills have a significant influence on the silence behavior.

In every organisation, individual members have the potential to speak up about important issues, but a growing body of research suggests that they often remain silent instead, out of fear of negative personal and professional consequences (Mohamad Idros, 2014; Y1ld1z, 2013; Zhang, Tsui and Wang, 2011). According to Face Negotiate Theory developed by Ting-Toomey (1988), it 
is important in communication to keep the message in order not to hurt or degrading the presenter or recipient information. Individuals from different cultures often consulted about face (Ting-Toomey, 1988). Based in this discussion, this study predicts that:

\section{$H_{4}$ : Expected of negative impact has a significant influence on the silence behavior.}

Management practices that are not aligned with organisational goals can have an adverse effect on the organisation (Mawhinney, 2009). Drawing on Organisational Climate Theory (Ashforth, 1985; Schneider and Reichers, 1983), Morrison and Milliken (2000) suggested that managements' implicit beliefs create a climate of silence as a collectively shared experience that is dangerous and/or futile to speak up on critical issues. In the hierarchical organisation, the top management will form the belief that they know better in every way than the subordinates. In addition, subordinates' behavior that express objections to or different ideas from those of a superior are seen as expressions of disrespect for the senior and therefore blameworthy. Due to these rules and credos, many people choose avoidance behavior even when they feel that an issue is important or that they have potentially important information to share (Zhang et al., 2011). Based in this discussion, this study assumes that:

\section{H5: Management practice has a significant influence on the silence behavior.}

\section{RESEARCH METHODOLOGY}

From the literatures presented in previous section, a conceptual model has been developed based on the Model of Employee Silence by Milliken et al. (2003). The model conjectures that the communication skills, expected of negative impact, and management practice may cause silence behavior among the staff in the higher learning institutions. The sampling frame of this study is the staffs in the higher learning institutions which refer to academic and non-academic staff. The present research employed self-administered questionnaire as an instrument of data gathering. The respondents are selected based on simple random sampling method. For this study, 200 questionnaires were distributed to the staff at four higher learning institutions in Selangor, Malaysia. After collecting back the surveys, only 136 have been returned, making the percentage of return rate is $68 \%$.

\subsection{Survey Instruments}

The survey adapted in the study is composed of questions which determine the issues about which staff remain silent and perceived results of silence. In this form, the survey was composed of 23 questions in total. There are 6 items concerning subjects which staff remains silent, 5 questions concerning communication in the higher learning institution, 6 questions regards to the expected of negative impact, and 6 questions concerning management practice. 5-graded Likert-type scale was used in the study.

\section{RESULTS AND DISCUSSIONS}

\subsection{Demographic Profile}

Table 1 provides a snapshot of the demographic characteristics of the respondents who are grouped into the following profiles such as types of higher learning institutions, gender, education level, and types of staff. Respondents consisted of staff at four higher learning institutions in Selangor, Malaysia which can be categorized as public and private universities. There are $54.4 \%$ of respondents from public university, while another 45.6 are from private university. A total of $103(75.5 \%)$ of respondents are female, and $24.3 \%$ of the respondents are male. Majority of the respondents have Master Degree as their highest education level. There is 
only $12.5 \%$ of respondents acquired education up to $\mathrm{PhD}$. Majority of the respondents in this study is an academic staff (61\%), and the balance (39\%) are non-academic staff.

Table 1: Demographic Profile of Respondents

\begin{tabular}{llcc}
\hline Variables & Descriptions & Frequencies & Percentages \\
\hline Types of University & Public University & 74 & 54.4 \\
& Private University & 62 & 45.6 \\
\hline Gender & Male & 33 & 24.3 \\
& Female & 103 & 75.7 \\
\hline Education Level & Degree & 31 & 22.8 \\
& Master Degree & 67 & 49.3 \\
& PhD & 17 & 12.5 \\
& Others & 21 & 15.4 \\
\hline Types of Staff & Academic Staff & 83 & 61.0 \\
& Non-Academic Staff & 53 & 39.0 \\
\hline
\end{tabular}

\subsection{The Extent of Silence Behavior}

The first research objective of this study is to identify the extent of silence behavior among staff. Table 2 reveals the results of one sample $t$-test analysis on the extent of silence behavior among staff in the higher learning institutions in Selangor. Result shows that staffs are moderately agreed that they preferred to remain silent and it is statistically significant at the $1 \%$. Hence, this result leads to the acceptance of $\mathrm{H}_{1}$.

Respondents revealed that the main reason for remain silence is they need to preserve the dignity of a higher management before express a sensitive matter. Further, they are not going to talk about sensitive issue in the faculty. Sometimes, they realized something fishy within the faculty, however, they unable to do anything to fix the problem. They also prefer to remain silent rather than express my opinions that can cause my top leader anger. According to the respondents, there is no point to express an opinion because it will not change the situation.

Table 2: The Extent of Silence Behavior among Staff

\begin{tabular}{|c|c|c|c|c|}
\hline \multirow{2}{*}{ Variable } & \multirow{2}{*}{$\mathbf{n}$} & \multirow{2}{*}{ Mean } & \multicolumn{2}{|c|}{ One Sample T-Test } \\
\hline & & & $t$-statistic & $p$ value \\
\hline Silence Behavior & 136 & 3.288 & 50.152 & $.000^{* * * *}$ \\
\hline
\end{tabular}

\subsection{Difference in Silence Behavior among Staff}

The second objective is to examine if there is any significant different in silence behavior among staff in different higher learning institutions. Panel A of Table 3 shows that there is a significant different in the extent of silence behavior among staff in different higher learning institutions and it is statistically significant at $1 \%$. Hence, this result leads to the acceptance of $\mathrm{H}_{2}$. The result reveals that staff in the public universities is more prefer to remain silent as compared to staff at the private universities. Perhaps, power distance structure in public organisation automatically introduces restraints against free communication (Rhee et al., 2014). Further, Panel B of Table 3 depicts that there is a significant different in the extent of silence behavior among academic and non-academic staff and it is statistically significant at $5 \%$ level. This result leads to the acceptance of $\mathrm{H}_{2}$. The result reveals that non-academic staff is more prefer to remain silent as compared to 
an academic staff. This result indirectly indicates that academic staffs are more vocal in express their opinion as this is important especially those involved student's matters.

Table 3: Silence Behavior among Staff in Different Higher Learning Institutions

\begin{tabular}{|c|c|c|c|c|c|}
\hline \multirow{2}{*}{ Demographic Profile } & \multirow{2}{*}{$\mathbf{n}$} & \multicolumn{2}{|c|}{ Silence Behavior } & \multicolumn{2}{|c|}{ Independent Sample t-test } \\
\hline & & Mean & SD & F-test & $p$ value \\
\hline \multicolumn{6}{|c|}{ Panel A: Higher Learning Institutions } \\
\hline Private University & 74 & 3.232 & 0.775 & \multirow{2}{*}{8.795} & \multirow{2}{*}{$.003^{* * *}$} \\
\hline Public University & 62 & 3.355 & 0.753 & & \\
\hline \multicolumn{6}{|l|}{ Panel B: Types of Staff } \\
\hline Academic Staff & 83 & 3.167 & 0.767 & \multirow{2}{*}{2.354} & \multirow{2}{*}{$.019^{* * *}$} \\
\hline Non-Academic Staff & 53 & 3.478 & 0.727 & & \\
\hline
\end{tabular}

\subsection{Factors Causing Silence Behavior}

This section will discuss the results for third objective, i.e. to investigate the factors influencing silence behavior among staff at the higher learning institutions. The summary results of the standard multiple regression analysis on the factors influencing silence behavior is presented in Table 4 . The regression of model $\left(F(3,136)=9.767, p\right.$ value $\left.=.000^{* * *}\right)$ is significant at the $1 \%$, and the overall fit of the model is moderate with adjusted $\mathrm{R}^{2}$ is $46.3 \%$ of the variation in the silence behavior. This indicates that the predictor variables in the model explained for approximately $46.3 \%$ of the total variability in the silence behavior.

Results in the Table 4 show that the expected of negative impact and management practice have a significant influence on the silence behavior among the staff in the higher learning institutions. Therefore, these results lead to the supporting of $\mathrm{H}_{4}$ and $\mathrm{H}_{5}$. Contrary, hypothesis $\mathrm{H}_{3}$ was not supported as a communication skill does not significantly influence the silence behavior among the staff. This finding indicates that the attitudes of higher management who fear receiving negative feedback from their staff contribute to silent behavior. Serving in the higher learning institutions which have high power distance culture makes these staffs are more likely to remain silence. Sometimes, expressing the negative information will be misunderstood as challenging the status of the higher management. The respondents revealed that their higher management did not like members who against them and they also perceived that their higher management will change the information to protect their self-interest.

In addition, the result of this study suggests that management practice create a climate of silence as a respondents' experience that is dangerous and/or pointless to speak up on critical issues. The present study finds that staffs who have fear of punishment of retaliation or being marginalized become reluctant to share information with their higher management. They do not dare to exposed negative information because this action will affect others in the faculty and from their experience; those who deliver negative information will be oblique / discriminated.

Table 4: Standard Multiple Regression Results on the Determinants of Silence Behavior

\begin{tabular}{lcccc}
\hline & Hyp. & Std. Beta Coefficient & $t$-statistic & $p$ value \\
\hline Intercept & & & 3.411 & $.001^{* * *}$ \\
Communication Skill & $\mathrm{H}_{3}$ & -0.018 & -0.226 & .822
\end{tabular}


Expected of Negative Impact

Management Practice
$\mathrm{H}_{4}$

$\mathrm{H}_{5}$
0.302

0.166
2.880

$.005^{* * *}$

1.598

\begin{tabular}{lc}
\hline Model Summary: & \\
$\mathrm{R}^{2}$ value & $48.2 \%$ \\
Adjusted R ${ }^{2}$ value & $46.3 \%$ \\
\hline Anova Results: & \\
F-value & 9.767 \\
Sig. value & $.000^{* * * *}$ \\
$\quad$ Obs. & 136 \\
\hline
\end{tabular}

Note: Association is significant at ${ }^{* * *} 1 \%$ level, ${ }^{* *} 5 \%$ level, respectively, using two-tailed tests.

\section{CONCLUSION}

Silence behavior occurred when the staff deliberately sparing his thoughts, information, and knowledge for enhancing his work at the workplace. Based upon a Model of Employee Silence developed by Milliken et al. (2003), this study identify the extent silence behavior and investigates the factors influencing silence behavior among staff in the higher learning institutions in Selangor, Malaysia. This cross-sectional quantitative study was performed on 136 academic and non-academic staff from public and private universities using survey questionnaire method.

Overall, the staff in the higher learning institutions especially those in public universities and in the position of non-academic staff preferred to remain silence because of they need to preserve the dignity of a higher authority before express a sensitive matter. Besides, they are not going to talk about sensitive issue in the organisation. These findings indicate that power distance orientation in the higher learning institutions fostered silence behavior among its staff. This finding is consistent with that of Rhee, Dedahanov and Lee (2014) who suggested that when leaders frequently use authority and power when dealing with low level subordinates, they will passively withhold ideas regarding solutions to problems.

The result of this study reveals that communication skills do not influence the silence behavior among the staff in the higher learning institutions. Respondents agreed that they need to follow the formal procedure in order to communication with their top management. Even though the information must be communicated by the subordinates to the superiors who are closest to them, they agreed that it is easy for them to express their opinion to their leaders. Perhaps, they did not have any problem in the process of distributing information in their university. With the right information dissemination strategies, the staffs in the higher learning institutions are able to exercise voice and express their ideas, information, and opinions.

Further, the findings of this study indicate that power distance lead the respondents to conceal work-related issues based on fear. As predicted, the relationship between expected of negative impact and management practice was significant towards silence behavior. The findings of this study reveal that in response to the possibility of punishment for retaliation or being marginalized, or that they might be discriminated, the staff concealed their negative information based on fear and self-protection. Finally, the finding of this study is consistent with the Face Negotiate Theory (Ting-Toomey, 1988). The respondents revealed that they preferred to silence because of the attitudes of their high management who fear receiving negative feedback from the faculty members. This indicates that universities' culture often preferred to save their face. Possibly, these are the main reason for the issues raised in the earlier section. No one preferred to be as whistleblower to report the wrongdoing cases to the higher management. Some of them 
just ignored the incidence of wrongdoing happened to avoid the negative impact towards them. Fear of retaliation or being marginalized as well as being misunderstood as challenging the status of the high management makes they keep silence about the wrongdoing cases. Besides, the respondents also perceived that their high management will change the information to protect their self-interest. Therefore, it is pointless for them to speak up on wrongdoing issues.

\subsection{Implications of the Study}

The findings in this study have an impact to the theoretical and practical implications. From the theory perspective, the findings of this study support the validity of the applied Model of Employee Silence developed by Milliken et al. (2003). In addition, the results of this study also consistent with the Face Negotiate Theory developed by Ting-Toomey (1988). Even though the model of employee silence has been developed in the past 14 years, but it is still relevant as an approach to investigate the silence behavior among employees. Therefore, for better understanding of the various factors which influence the silence behavior among the staff in the higher learning institutions, the Model of Employee Silence and Face Negotiate Theory can be applied for future research.

In addition, this study offers a practical implication as this study could serve as a guide for Ministry of Education. The findings show that it is difficult to mitigate silence in high-power distance oriented organisation such as public and private universities because these institutions follow a hierarchical position in that at each level of ranks, the staffs responds to directions and order from their top management. In consequences of this result, strategies to encourage the staff to voice out their opinion must be develop in order to effectively mitigate silence behavior. In addition, in order to enhance the role of the employees' voice, the top management in the higher learning institutions should establish a climate of participation by sharing information and involving all level of staff regardless academic or non-academic members in the decision-making process.

\section{REFERENCES}

Ashforth, B. E. (1985). Climate formation: Issues and extensions. Academy of Management Review, $10,837-847$.

Bagheri, G., Zarei, R., \& Aeen, M. N. (2012). Organizational silence (basic concepts and its development factors). Ideal Type of Management, 1(1), 47-58.

Blau, P. (1964). Exchange and Power in Social Life. New York: Wiley

Dedahanov, A. T., Lee, D. H., \& Rhee, J. (2016). Silence as a mediator between organizational factors and stress. Journal of Managerial Psychology, 31(8), 1251-1264.

Deverell, E., Olsson, E. K., Wagnsson, C., Hellman, M., \& Johnsson, M. (2015). Understanding public agency communication: The case of the Swedish Armed Forces. Journal of Public Affairs, 15(4), 387-396.

Griffin, E. A. (2003). A First Look at Communication Theory. (5th Ed.). Boston: McGraw-Hill.

Hurtado, S., Milem, J. F., Clayton-Pedersen, A. R., and Allen, W. (1998). Enhancing campus climates for racial/ethnic diversity: Educational policy and practice. The Review of Higher Education ,21(3), 279-302.

Huzaila-Majid, M., \& Singaravelloo, K. (2017). Budgetary mismanagement: A qualitative study of the Malaysian Public Sector. Malaysian Journal of Economic Studies, 54(2), 255-267. 
Jahanzeb, S., Fatima, T., \& Malik, M. A. R. (2018). Supervisor ostracism and defensive silence: A differential needs approach. European Journal of Work and Organizational Psychology, 1-11.

Juhari, A. (1996) Asas Pengurusan. Pulau Pinang: Universiti Sains Malaysia.

Kiffin-Petersen, S. A. (2018). Ashamed of your shame? How discrepancy self-talk and social discourse influence individual shame at work. Social Functions of Emotion and Talking About Emotion at Work, 232.

Marcus, L. R. (2000). Staff diversity and the leadership challenge. Equity and Excellence in Education, 33(2): 61--67.

Mawhinney, T. C. (2009). Identifying and extinguishing dysfunctional and deadly organizational practices. Journal of Organizational Behavior Management, 29(3-4), 231-256.

Milliken, F. J., Morrison, E. W. \& Hewlin, P. F. (2003). An exploratory study of employee silence: Issues those employees don't communicate upward and why? Journal of Management Studies, 40(6), 1353-1376.

Mohamad Idros, M. S. (2014). The silence behavior among cadet officer in National Defence University of Malaysia. (Unpublished Master Dissertation), National Defence University of Malaysia.

Morrison, E. W. \& Milliken, F. J. (2000). Organizational silence: A barrier to change and development in a pluralistic world. Academy of Management Review, 25, 706-725.

Rhee, J., Dedahanov, A. \& Lee, D. (2014). Relationships among power distance, collectivism, punishment, and acquiescent, defensive, or prosocial silence. Social Behavior and Personality, 42(5), 705-720. Doi: 10.2224/sbp.2014.42.5.705.

Schneider, B., \& Reichers, A. E. (1983). On the etiology of climates. Personnel Psychology, 36, 19-39.

Tangirala, S. \& Ramanujam, P. (2008). Employee silence on critical issues: The cross level effects procedural justice climate. Personnel Psychology, 61, 37-68.

Ting-Toomey, S. (1988). Intercultural Conflict Style: A Face-Negotiation Theory. Baverly Hill, Calif: Sage.

Yildiz, E. (2013). Enigma of silence in organizations: What happens to whom and why? Beykent University Journal of Social Sciences, 6(2), 30-44.

Zhang, A. Y., Tsui, A. S. \& Wang, D. X. (2011). Leadership behaviors and group creativity in Chinese organizations: The role of group processes. The Leadership Quarterly, 22, 851-862.

Tülübaş, T., \& Celep, C. (2014). Causes of faculty members' silence. Hacettepe University Journal of Education, 29(1), 280-297.

Yaman, E., \& Ruçlar, K. (2014). Organizational silence in universities as the predictor of organizational culture. Journal of Higher Education \& Science, 4(1), 36-50. 